\title{
Apple Maturity Prediction: An Extension Tool to Aid Fruit Storage Decisions
}

\author{
Randolph Beaudry', \\ Philip Schwallir', and \\ Marian Lennington ${ }^{1}$
}

Additional index words. CA storage, ethylene, carbon dioxide, oxygen

Summary. Due to the the extremely high level of competition in the marketplace for stored apple fruit, the need for quality maintenance during storage is critical. Quality analysis of fruit at harvest supports the contention that there is a harvest period during which fruit picked for long-term controlled-atmosphere storage maximize grower returns. The apple maturity program used in Michigan for determining this optimal harvest period-or window -incorporates a bloom date-based prediction and fruit maturity analyses. Techniques used in collecting and disseminating maturity information and its interpretation are discussed.



ontrolled-atmosphere (CA) storage technology has permitted an expansion of the time and area in which an apple crop can be marketed. In the United States, high-quality fruit from each of the major production areas compete in the marketplace for 6 to 9 months following harvest. In recent years, competition has escalated with the development of a more global marketplace in which freshly harvested, contra-seasonal apple fruit from the southern hemisphere are sold alongside CAstored fruit from the northern hemisphere. The present high level of competition has enhanced the already critical need for maximizing fruit quality and storability.

Department of Horticulture, Michigan State University, East Lansing MI 48824.

${ }^{2}$ District Extension Horticultural Agent, Kent Co., Mich. 
Harvesting apple fruit at the proper stage of maturity is an important cultural tool we have at our disposal to optimize fruit storability. It has been shown numerous times that storability is highly dependent on fruit maturity at harvest. Monitoring the maturity status of fruit, therefore, provides the orchardist with the capacity to manage the storability of the harvested fruit through timely harvesting. Unfortunately, harvest season factors such as weather, labor, and varying stages of color development generally make it unfeasible to get all the fruit at ideal maturity. Nevertheless, knowledge of the storage potential of the fruit would permit their segregation for long-, mid-, and short-term storage. Present trends in reduced room size and more rapid establishment of CA conditions has made storage segregation an increasingly common practice.

In Michigan, as in other appleproducing areas, an apple maturity program has been developed as a tool to aid orchardists, packinghouse field workers, storage operators, horticulture agents, and researchers in managing fruit maturity and storability. The large number of apple cultivars grown in Michigan and significant regional differences in climate, soil type, and cultural practices result in a wide variance in maturation between and within cultivars.

\section{Fruit development and maturation}

The origins of using cultural tools to control the processes of fruit development and maturation date to antiq-



Fig. 1. Apple fruit developmental stage, growth, respiration, internal ethylene concentration, and storage life as a function of time (adapted from Lay 1984). uity. The Bible makes reference to farmers piercing the skin of sycamore figs to induce rapid growth and ripening (Amos 7:14). As we presently understand them, the sequential stages of growth, maturation, ripening, and senescence of apple fruit can be summarized in a rather general manner (Fig. 1). As depicted in Fig. 1, the onset of ripening is associated with a rapid increase in the respiration of detached fruit. This rise in respiration is referred to as the respiratory climacteric, which is accompanied by a many-fold increase in the rate of ethylene synthesis and, importantly, a decline in storage life. Ethylene plays a central role in ripening-initiating and/or accelerating numerous physiological processes that we perceive as changes in dessert quality (i.e., red coloration, firmness, soluble solids, acidity, etc.). The complete role of ethylene is still being elucidated. It is hypothesized that ethylene is the molecule responsible for ripening in all fruits sensitive to ethylene (Burg and Burg, 1965). However, there is still debate as to whether ripening can take place in the absence of ethylene. In apple, for instance, significant changes in firmness, skin color, and starch content take place prior to a detectable increase in the internal ethylene concentration (Lau et al., 1986).

The stage of fruit development at harvest has a significant impact on the potential quality of the stored product. Very immature fruit never achieve full quality potential after harvest in that they do not tend to develop adequate sugars or varietal flavors and can undergo shrivel and excessive weight loss during storage. Over-mature fruits, on the other hand, are prone to excessive ripening and are more susceptible to bruising, flesh browning, senescent breakdown, and decay during storage. Advancing apple fruit maturity is also related to a decline in scald susceptibility among scaldsusceptible cultivars (Smock and Southwick, 1945). Despite potential for a loss in storability due to advancing maturity, a decline in scald susceptibility from a delay in harvest may be of greater economic benefit. This may be especially true if diphenylamine (DPA, an antioxidant used to prevent scald development) does not make it through the Environmental Protection Agency s re-registration process now underway. Research has indicated that exposure of apple fruit to low temperatures for extended periods prior to harvest can also attenuate scald development (Bramlage and Barden, 1989). In the years to come, we may see apple maturity programs that include a scald susceptibility rating based on our increased understanding of this problem.

\section{Effect of harvest date on grower returns}

The goal of apple maturity programs is to identify a harvest period (or window ) that optimizes the relationship between declining storage potential (from decreasing firmness and increasing susceptibility to disorders associated with overmaturity) and increasing dessert quality (from improvement in coloration, size, and flavor). Furthermore, it is necessary to predict accurately the harvest window sufficiently in advance of harvest (5 to 10 days is usually adequate) to give the grower lead time for planning and organizing harvest.

An assumption implicit in the use of maturity programs for scheduling the apple harvest is that the poststorage value of the fruit is at a maximum if it has been picked during the harvest window and is lower if it has been harvested later in the season as firmness (or some other quality attribute) declined sufficiently to compromise salability. This assumption is largely untested. We attempted to gather supportive evidence for this assumption by examining the effects of time-dependent changes in crop value. Crop value was considered to be a function 
Table 1. Thresholds for the quality parameters of size, color, and firmness of McIntosh apple fruit and their effects on fruit use. Fruit values $(\$ / \mathrm{lb})$ associated with each use category are: juice $=0.04$; sauce $=0.07$; fresh $(\mathrm{bag})=$ 0.12 ; fresh (tray) $=0.15$. A premium of $\$ 0.03 / \mathrm{b}$ was added to potentially freshmarket fruit placed in CA.

\begin{tabular}{lccc}
\hline & \multicolumn{3}{c}{ Quality attributes } \\
\cline { 2 - 4 } Fruit & $\begin{array}{c}\text { Size } \\
\text { (inches) }\end{array}$ & $\begin{array}{c}\text { Color } \\
\text { (percent red) }\end{array}$ & $\begin{array}{c}\text { Firmness } \\
\text { (lb) }\end{array}$ \\
\hline Juice & $<2.5$ & $<30$ & $<11$ \\
Sauce & $<2.5$ & $<30$ & $11-15.5$ \\
Fresh (bag) & $2.5-2.75$ & $>30$ & $>15.5$ \\
Fresh (tray) & $>2.75$ & $>30$ & $>15.5$ \\
\hline
\end{tabular}

of yield, fruit size and size distribution, fruit color (red coloration in most instances), and fruit firmness.

As a test case, time-dependent changes in Macspur McIntosh fruit quality characteristics were assessed for their influence on fruit value. Fruit were harvested every 3 to 4 days beginning 17 Aug. 1992. On each date, fruit weight, color, and firmness for 10 fruit selected at random from three trees in a variety test block at the Clarksville Horticultural Research Station, Mich. Thresholds for fruit size, color, and firmness were established in order to partition the crop into fresh or processing categories (Table 1). The firmness threshold was established based on a $90 \%$ firmness retention for fruit rapidly cooled and placed under CA conditions (unpublished data). That is, fruit with a firmness measurement by Magness-Taylor penetrometer of $14.5 \mathrm{lb}$ would be expected to exit CA storage at $13 \mathrm{lb}$.

The fresh-market and processing fruit portions were further subdivided. Fresh-market fruit were categorized as those most suitable for bagged or tray-

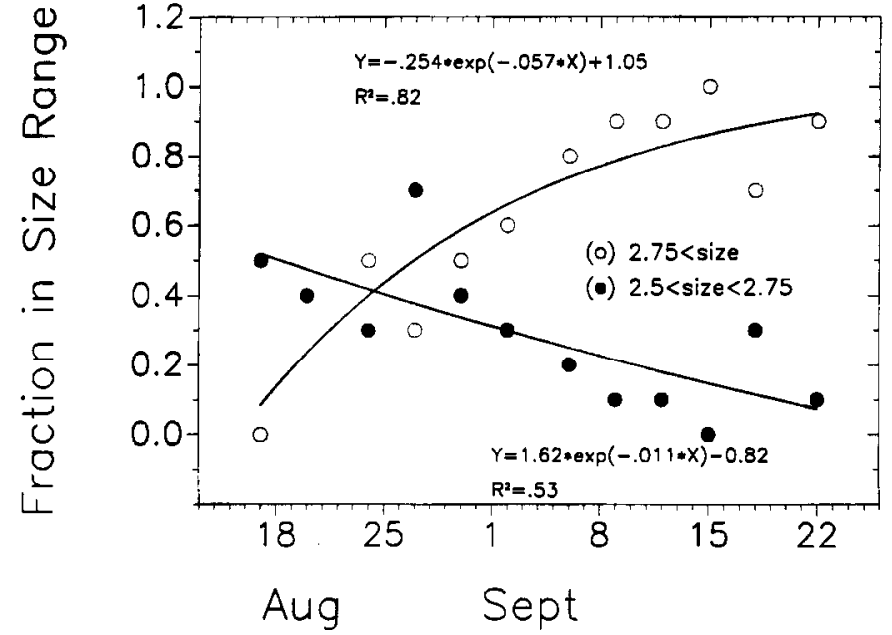

Fig. 3. Fraction of McIntosh apple fruit in the small ( $\leq 2.5-$ and $<2.75$-inch) and large $(\geq 2.75-$ inch) size ranges during the 1992 harvest season.

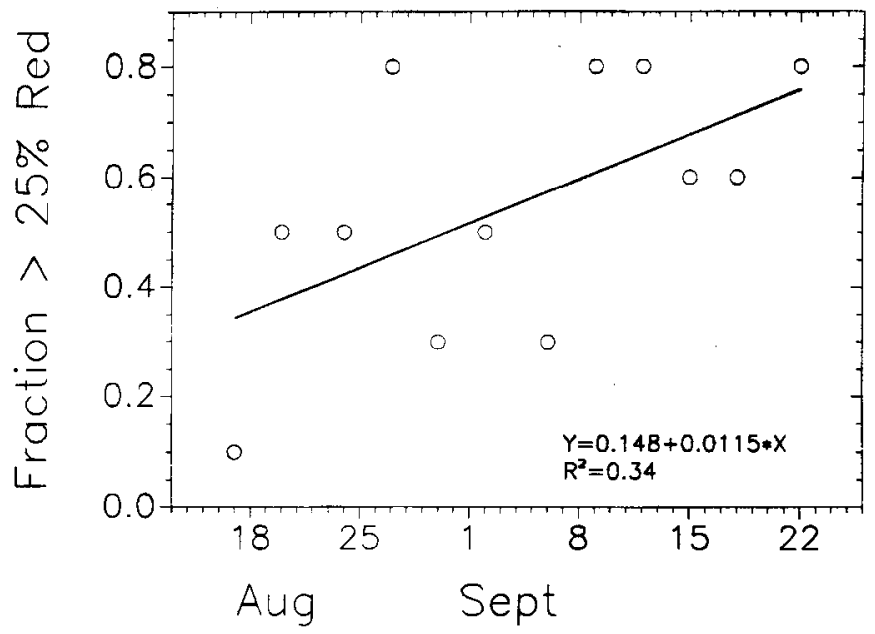

Fig. 4. Trend for the fraction of McIntosh fruit with $>25 \%$ red coloration during the 1992 harvest season. packed fruit and the processing fruit were similarly subdivided into juice or sauce fruit. A per-pound value was established for fruit in each use category based on past Michigan pricing. The sum of the post-CA values of the fresh market and processing portions

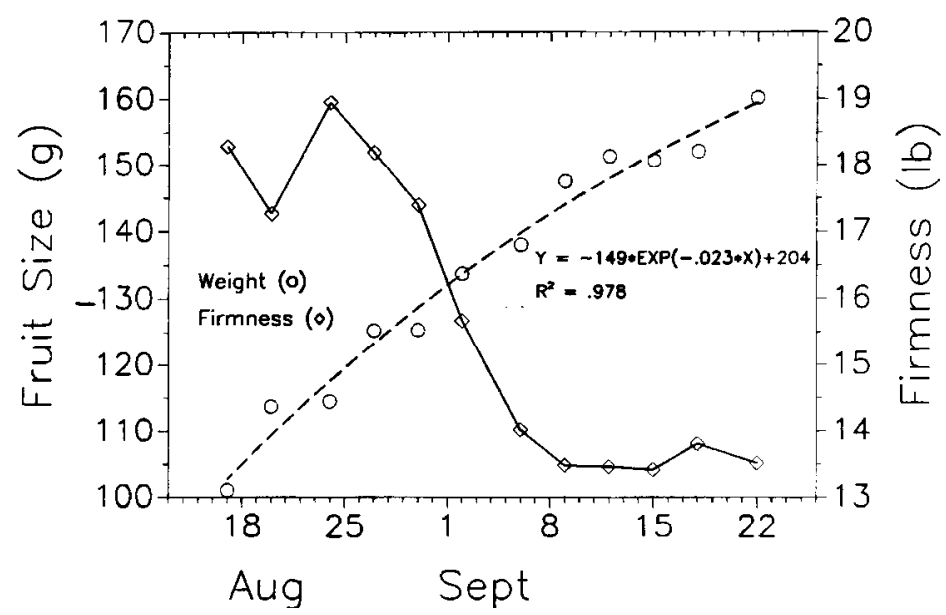

Fig. 2. Firmness and weight trends for McIntosh apple fruit during the 1992 harvest season. on a per-acre basis is reported.

Fruit firmness declined $\approx 5 \mathrm{lb}$ between 27 Aug. and 8 Sept., while fruit weight increased steadily from the first harvest (Fig. 2). Fruit diameter was estimated based on its relationship with fruit weight [inches diameter $=$ $0.00752 \times \mathrm{g}$ fruit $\mathrm{wt}+1.8 ; r^{2}=0.95$, $\mathrm{n}=40$; data not shown]. The portion of fruit in the tray pack size range (>2.75 inches) increased as those in bag size range $(>2.5$ and $<2.75)$ declined (Fig. 3). Finally, there was a general trend toward a greater proportion of fruit with acceptable color with harvest date (Fig. 4). The portion of the fruit crop in each of the use categories was estimated and the combined effect on crop value was calculated (assuming 500 bushels/acre on 17 Aug.) in dollars per acre returned to the grower. Crop value increased as color and fruit size distributions favored fresh-market fruit until 2 Sept. (Fig. 5). Note that the portion of fruit 


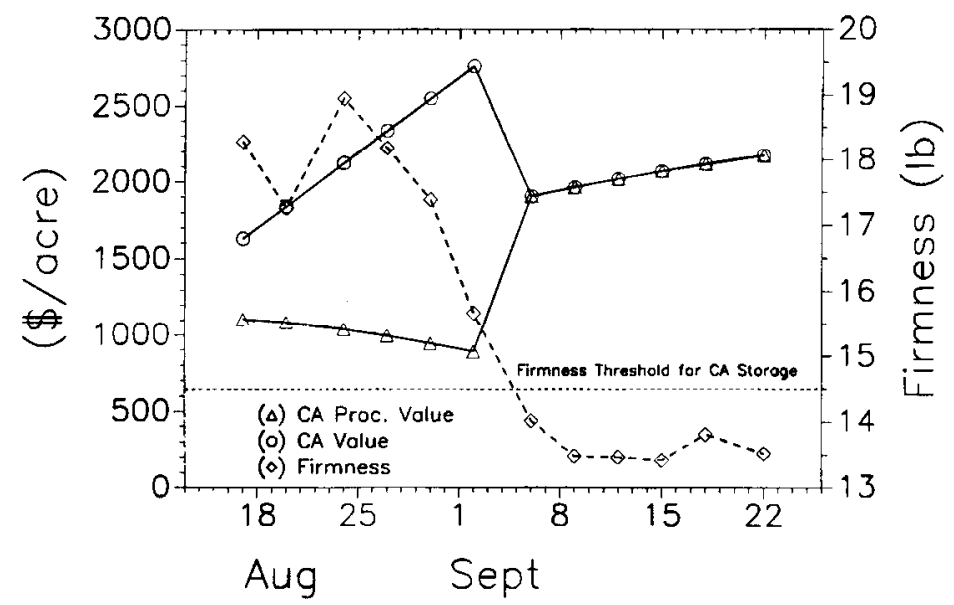

Fig. 5. Predicted crop value of McIntosh fruit following removal from long-term CA storage when harvested at different dates in the 1992 season. The decline in firmness below the threshold level of $14.5 \mathrm{lb}$ marks the harvest date at which fruit would be expected to emerge from CA with insufficient firmness for fresh-market sales.

emerging from CA and directed toward processing (due to low color or insufficient size) declines until this date. After this date, fruit stored in CA would be expected to be too soft, on average, for fresh market use and would be more suitable for processing (e.g., sauce).

The modeled changes in the value of a CA-stored crop serve to affirm the assumption that it is of economic benefit to harvest the most-mature fruit possible while avoiding excessive firmness loss. Even so, the optimal harvest window for a given variety of apple is dependent on the needs of the grower. By identifying the long-term CA storage window, fruit destined for shorter CA storage durations and air storage would normally be harvested after this date.

A harvest model such as that described is rather unwieldy. However, simple and reliable alternatives exist. Generally, several easily determined harvest indices are used to describe the fruit s progress through its maturation phase and, by extrapolation, can be used to predict harvest windows. Most maturity programs use the harvest indices of fruit firmness and starch index (an index based on starch content). Other often useful indices include internal ethylene levels, readiness to synthesize ethylene, soluble solids, seed color, and length-of-season formulae.

\section{Apple maturity program in Michigan}

The Dept. of Horticulture at Michigan State Univ. (MSU), in cooperation with the Michigan Cooperative Extension Service (MCES), has developed an apple maturity program serving the various fruit growing regions throughout the state. Cooperators in the program attempt to provide growers and storage operators with sufficient information to enable them to make harvest decisions that will optimally suit their operation.

The maturity program output has two phases during the growing season, an early estimate based on bloom date and postbloom temperatures and a more-detailed maturity analysis during the harvest season based on fruit maturity indices. The early estimate acts to alert growers as to the relative earliness or lateness of the season, helping the scheduling of picking crews, storage arrangements, etc. In addition, it serves to help raise the level of awareness regarding the indice-based maturity analysis to follow. This later, more-detailed maturity analysis is designed to help the grower and packing shed operators optimally harvest and store fruit according to their needs.

Harvest prediction based on bloom date. Early in the season (March-April), questionnaires are sent out to several hundred grower-cooperators in 30 localities throughout the lower peninsula of Michigan. We ask for full $(>80 \%)$ bloom dates on McIntosh, Jonathan, and Red Delicious cultivars. In addition, we obtain maximum and minimum temperatures for each locality for a period of 30 days following full bloom. The following formulae are used to predict the harvest date for long-term CA by calculating the number of days past full bloom when fruit are first suitable for harvest:
McIntosh (average of the following three formulae):

1) Days $=120 \pm 1$ day per ${ }^{\circ} \mathrm{F}$ difference between the average minimum temperature of the 15 days following full bloom and 50F.

2) Days $=144.5-0.057 \times\{$ sum of daily positive differences between the day s mean temperature [(maximum + minimum)/2] and base 40F for 21 days following full bloom].

3) Days $=226-0.058 \times$ \{sum of daily differences between the days mean temperature [(maximum + minimum)/2] and base OF for 30 days following full bloom].

Jonathan

1) Days $=137 \pm 1$ day per ${ }^{\circ} \mathrm{F}$ difference between the average minimum temperature of the 15 days following full bloom and 50F.

Red Delicious

1) Days $=143 \pm 1$ day per ${ }^{\circ} \mathrm{F}$ difference between the average minimum temperature of the 15 days following full bloom and 50F.

These estimates are provided to our regional CES horticulture agents who, in turn, distribute them to virtually every commercial fruit grower in the state $(>1400)$ through subscriptions to CES newsletters and, to a limited extent, through meetings and code-a-phones. We have found that, in Michigan, these harvest date estimates are usually quite reliable, usually coming within a few days of our longterm storage dates based on actual fruit analyses.

Harvest prediction based on fruit analyses. This portion of the maturity program involves monitoring the progress of apple fruit through the latter stages of maturation and the initial stages of ripening. Based on the fruit s stage of development, we recommend optimal harvest dates for long-term, intermediate, and short term CA storage. The program covers five somewhat distinct production areas, supporting each production area with its own regional maturity program. The regional fruit maturity centers are in the southwest, west central, west, northwest, and southeast portion of the state. Apple cultivars of primary importance (fresh market and processing) are assessed for maturity status on a weekly basis. Major apple varieties include McIntosh, Jonathan, Empire, Golden Delicious, Red Delicious, Northern Spy, 
Idared, and Law Rome.

In each of the five regions, fruit from eight to 10 representative orchard blocks are sampled and analyzed by trained CES personnel. Weekly sampling begins 2 to 3 weeks before the bloom date harvest estimate and continues for 1 or 2 weeks after the longterm storage date. Apple samples are composed of 10 fruit per orchardvariety-date combination. Three to five sites are sampled per variety. Maturity assessments are primarily dependent on three maturity indices: starch index, firmness, and internal ethylene.

Each regional center is outfitted with a gas chromatograph, MagnessTaylor firmness tester, and starch index iodine solution ( $10 \mathrm{~g} \mathrm{KI}$ and $40 \mathrm{~g}$ I, per 4 liters of water). The starch index is estimated based on Ontario (Chu, 1988; Priest and Lougheed, 1988) and North Carolina (Saltveit and Hale, 1982) starch index charts. In addition to this information, we estimate percentage of red coloration and have included estimates of the onset of the ethylene climacteric based on a technique by Dilley and Dilley (1985). The rapidity of the development of the ethylene climacteric is related to the maturity of the fruit and can be used to predict the optimal harvest date for some varieties. However, internal ethylene levels, which are predicted by this technique, are not always correlated well with poststorage quality (Blanpied and Silsby, 1992; Jobling, 1993).

To determine target levels for firmness and starch index, we have developed a set of guidelines (Table 2) that are, in part, based on the apple industry s suggested thresholds. In addition, we generally recommend that the harvest for long-term CA storage be completed before $20 \%$ of the fruit have internal ethylene levels that exceed 0.2 parts per million. These guidelines are used by maturity program
Table 2. Guidelines for acceptable ranges for starch index and firmness for long-term CA storage of major apple fruit cultivars in Michigan

\begin{tabular}{lcc}
\hline Cultivar & $\begin{array}{c}\text { Starch-iodine } \\
\text { index }\end{array}$ & Firmness (lb) \\
\hline McIntosh & $4-6$ & $4.5-15$ \\
Jonathan & $3-5.5$ & $15.5-16$ \\
Jonagold & $3-5.5$ & $15-16$ \\
Empire & $4.5-5.5$ & $16-17$ \\
& & $18-19$ \\
& & for export \\
Red Delicious & $2.5-4$ & $17-18$ \\
Golden Delicious & $3-5$ & $15-17$ \\
Idared & $3-4$ & $14.5-16$ \\
Mutsu & $3-4.5$ & $16-17.5$ \\
Law Rome & $3-5$ & $18-19$ \\
\hline
\end{tabular}

personnel throughout the season for making storage recommendations.

In the maturity reports, information is arranged by cultivar, date, strain, and location, as shown in Fig. 6. Standard desktop publishing software used

1992 APPLE MATURITY WEEKLY SUMMARY Researcher: Dr. Randy Beaudry, Agent: Philip Schwallet, Examiner: Robin Rasch

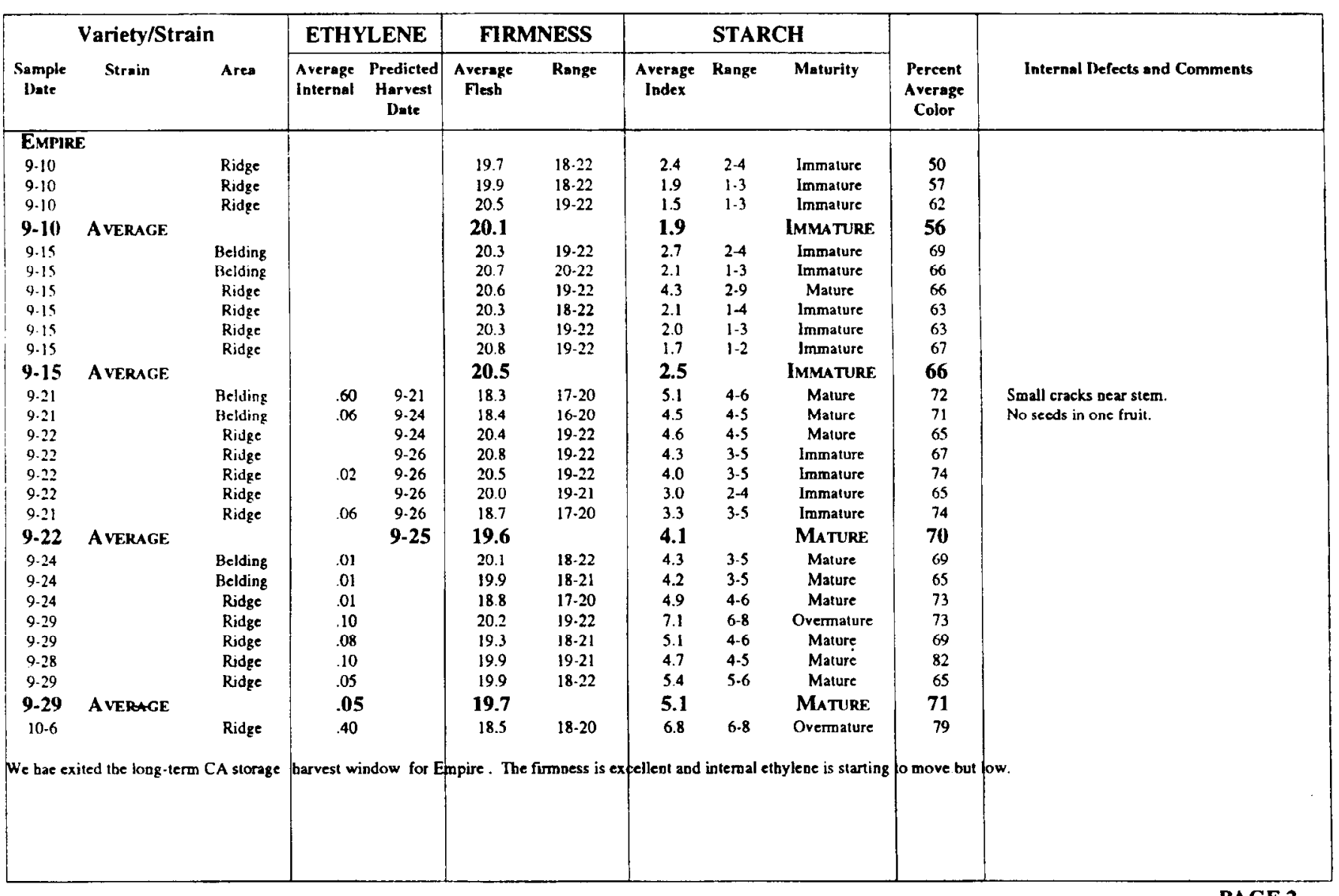

Fig. 6. Weekly summary form for Empire apple fruit from the Peach Ridge area for the 1992 harvest season used in that year s MSU apple maturity program. Summary form is p. 2 of a 5-page report. 
nologies being used for rapidly establishing and maintaining suitable CA conditions, Storage operators report that there has been a major improvement in quality of apple fruits from CA storage since these technologies have been introduced in Michigan in 1986.

The vitality of the apple industry in the coming years can be ensured by continued implementation of fruit quality improvement programs such as the apple maturity program described here. Its sole purpose is to improve grower, packinghouse field worker, and storage operator decisions. We consider it one of many useful management tools available to help the apple industry grow, store, and market a quality apple.

\section{Literature Cited}

Blanpied, G.D. and K.L. Silsby. 1992. Predicting harvest date windows for apples. Cornell Coop. Ext. Bul. 221.

Bramlage W.J. and C.L. Burden. 1989. Predictability of scald susceptibility of apples, p. 137-143. In: J. Fellman (ed.). Intl. Controlled. Atmosphere Res. Conf. 5th Proc.

Burg, S.P. and E.A. Burg. 1965. Ethylene action and the ripening of fruit. Science 148:398-399.

Chu, C.L. 1988. Starch-iodine test for determining maturity and harvest dates of Empire, Idared, and Spartan apples. Ont. Min. of Agr. and Food Bul. 88-090.

Dilley, C.L. and D.R. Dilley. 1985. New technology for analyzing ethylene and determining the onset of the ethylene climacteric of apples, p. 353-362. In: S.M. Blankenship (ed.). Natl. Controlled Atmosphere Res. Conf. 4th Proc.

Lau, O.L. 1984. Maturity measurements of the major B.C. apple cultivars and their impact on storage potential. Proc. 16th Annu. British Columbia Fruit Growers Assn. Hort. Forum, p. 55-68.

Lau, O.L., Y. Liu, and S.F. Yang 1986. Effects of fruit detachment on ethylene biosynthesis and loss of flesh firmness, skin color, and starch in ripening Golden Delicious apples. J. Amer. Soc. Hort. Sci. 111:731-734.

Priest, K.L. and E.C. Lougheed. 1988. Evaluating maturity of McIntosh and Red Delicious apples. Ont. Min. of Agr. and Food, Bul. 88-117.

Saltveit, M.E. and S.A. Hale. 1982. Determining the maturity of North Carolina apples: The starch-iodine staining technique. North Carolina Agr. Ext. Serv.

Smock, R.M. and F. W. Ridley. 1945. Studies on storage scald of apples. Cornell Agr. Ext. Bul. 813. 